\section{Immunolocalisation of leukaemia inhibitory factor in the cornea}

${ }^{1}$ Tennent Institute of Ophthalmology Gartnaval General Hospital 1053 Great Western Road Glasgow G12 OYN, UK

${ }^{2}$ Princess Alexandra Eye Pavilion Chalmers street Edinburgh EH3 9HA, UK

${ }^{3}$ Department of Developmental Sciences University of Edinburgh Hugh Robson Building George square EH8 9DX UK

Correspondence:

K Ramaesh

Tennent Institute of Ophthalmology Gartnavel General Hospital 1053 Great Western Road Glasgow, G12 OYN, UK Tel: +44 1314415037 Fax: +441412112054 E-mail: k.ramaesh@ talk21.com

Received: 27 August 2003 Accepted: 6 November 2003

Published online: 2 April 2004

\begin{abstract}
Aim Leukaemia inhibitory factor (LIF) is a pleotrophic cytokine expressed in a variety of cell types, and have shown to regulate stem cell proliferation, vascular genesis, inflammation, and immunity in various locations. Expression of LIF and its role in the cornea have not been studied previously. In this study, we examined the expression of LIF in the cornea.

\section{Materials and method}

Immunohistochemistry was performed using polyclonal LIF antibodies, and Avidin-Biotin ABC complex on cultured human corneal epithelium corneal fibroblasts and wild-type murine corneal epithelium.

Results LIF was detected in the cytoplasm of murine corneal epithelium, cultured human corneal epithelium, and fibroblasts. The expression of LIF was mainly cytoplasmic. Conclusion LIF is expressed in the corneal epithelium and fibroblasts. It may have an important role in the maintenance of homeostasis of the corneal epithelium and cornea stroma. Further studies are necessary to elucidate the role of LIF in the cornea.

Eye (2004) 18, 1006-1009. doi:10.1038/sj.eye.6701394

Published online 2 April 2004
\end{abstract}

Keywords: leukaemia inhibitory factor; corneal epithelium; and fibroblasts

\section{Introduction}

Leukaemia inhibitory factor (LIF) is a pleotrophic cytokine expressed in a variety of cell types in vitro, which include activated $\mathrm{T}$ lymphocytes, monocytes, mast cells neuronal cells, dermal keratinocytes, fibroblasts and endothelial cells, intestinal mucosal, respiratory mucosal, and retinal pigment epithelial cells. ${ }^{1-5}$ LIF belongs to a group of cytokines that includes ciliary neurotropin factor, IL-6, Ct-1, $\mathrm{OM}$, and IL-11. ${ }^{5}$ All the groups members elicit
K Ramaesh ${ }^{1}$, T Ramaesh ${ }^{2,3}$, JD West ${ }^{3}$ and B Dhillon ${ }^{2}$ different biological effects through the GP-130 signal transducing subunit as a common receptor. $^{5}$

Li $e t a l^{6,7}$ first reported the expression of LIF mRNA in cultured human corneal epithelial cells and keratocytes. The regulatory function of LIF in a variety of locations including stem cell proliferation, vascular genesis, inflammation, and immunity has been recently elucidated. ${ }^{8-11}$ However, the role played by LIF in the cornea is largely unexplored. In this study, we examined the corneal expression of LIF.

Material and methods

\section{Culturing human corneal epithelial cells}

Corneal epithelial cells were cultured according to accepted previous methods. ${ }^{12,13}$ Briefly, donor human corneal buttons maintained in organ culture media were obtained from the Manchester Eye bank. A measure of $2 \mathrm{~mm}$ explants from three different donors were prepared after removing central $8 \mathrm{~mm}$ of cornea. Explants were incubated with $0.1 \%$ trypsin and EDTA for $2 \mathrm{~h}$ at $37^{\circ} \mathrm{C}$ in $5 \% \mathrm{CO}_{2}$. Single cells were isolated and plated on growth-arrested 3T3-J2 feeder layer containing Green's media. The medium was changed every third day. The culture reached $70-80 \%$ confluence on day 14 . 3T3 cells were removed by vigorous pipetting. The remaining $3 \mathrm{~T} 3$ cells were removed with $0.01 \%$ trypsin for $15 \mathrm{~s}$. The epithelial cells were then allowed to reach confluence. After 3 weeks, the epithelial cells became stratified. Epithelial sheets were separated from the culture dish with dispase $(2 \mathrm{mg} / \mathrm{ml}$ in DMEM-Ca free and $10 \mathrm{FCS}$ ) and fixed in $4 \%$ paraformaldehyde for $4 \mathrm{~h}$.

\section{Culturing human corneal fibroblasts}

Corneal fibroblasts were cultured according to accepted previous methods. ${ }^{6,14}$ Human corneas 
were obtained from Manchester Eye Bank. Central $8 \mathrm{~mm}$ corneal buttons from three different donors were fashioned after removing the endothelium and the epithelium. The corneal stroma was cut into $2 \times 2 \mathrm{~mm}$ pieces and incubated in fibroblast growth medium containing DMEM, 2 mM L-glutamine, 10\% foetal calf serum and $100 \mathrm{IU} / \mathrm{ml}$ penicillin and streptomycin (all from Sigma). Upon confluence, the cells were passaged into cell culture flasks. Human corneal fibroblasts (passage 4) were cultured on cover slips (Sigma Grace Bio-Labs) according to manufacturer's instructions and incubated at $37^{\circ} \mathrm{C}$ in a $\mathrm{CO}_{2}$ incubator. After $48 \mathrm{~h}$, the cells were washed in PBS twice and fixed in $4 \%$

paraformaldehyde at room temperature for $15 \mathrm{~min}$. After two washes in PBS, the cells were dehydrated through graded concentrations of ethanol.

\section{Mouse cornea}

Six wild-type mice were killed by cervical dislocation and their eyes were removed and fixed in $4 \%$ paraformaldehyde for $4 \mathrm{~h}$. To facilitate sectioning, lenses were removed and the eyes were processed in paraffin wax. All animal procedures were performed in accordance with the ARVO Statement for the Use of Animals in Ophthalmic and Vision Research.

\section{Histological and immunological techniques}

Sections of eyes and the epithelial sheets cut at $7 \mu \mathrm{m}$ were mounted on poly-L-lysine coated slides and deparaffinised sections were treated with $100 \%$ ethanol. For immunostaining, both the sections (eyes and the epithelial sheath) on the slides and the fibroblasts on the cover slips were treated as follows. ${ }^{4}$ First, they were incubated with $3 \%$ hydrogen peroxide for $20 \mathrm{~min}$ to remove endogenous peroxidase activity, then rehydrated with $70 \%$ ethanol, and washed in PBS. The specimens were treated with normal rabbit serum for $30 \mathrm{~min}$ to block the nonspecific binding of antibodies and then incubated overnight at $4{ }^{\circ} \mathrm{C}$ with primary LIF antibody (Santa Cruz Goat polyclonal IgG, stock diluted 1:500). The specimens were then treated for $30 \mathrm{~min}$ with secondary antibody (biotinylated, anti-goat IgG, Vectastain ABC Kit) diluted 1:200 in blocking serum, washed in PBS, and then incubated for 30 min with $A B C$ complex. After washing in PBS, the binding antibody was visualised by $3,3^{\prime}$-diaminobenzidine (DAB, Sigma). All the specimens were then lightly counterstained with haematoxylin. Control slides and cover slips were incubated with normal rabbit serum, but otherwise treated in the same way.

\section{Results}

Mouse cornea

LIF expression was cytoplasmic and expressed in all layers of the corneal epithelium (Figure 1a and b). LIF expression was detected in all samples exmained. The superficial layers showed intense LIF expression. The basal layers showed weaker staining for LIF. LIF expression was present in limbal, paracentral, and central corneal epithelium. The endothelium and corneal stroma did not show LIF expression. Cultured corneal epithelial sheets expressed LIF in the cytoplasm and was detected in all layers of the corneal epithelium (Figure 1c and d). Similar to murine cornea, the superficial layers showed intense LIF expression. In the cultured corneal fibroblasts, LIF expression was detected in the cytoplasm (Figure 1e and f).

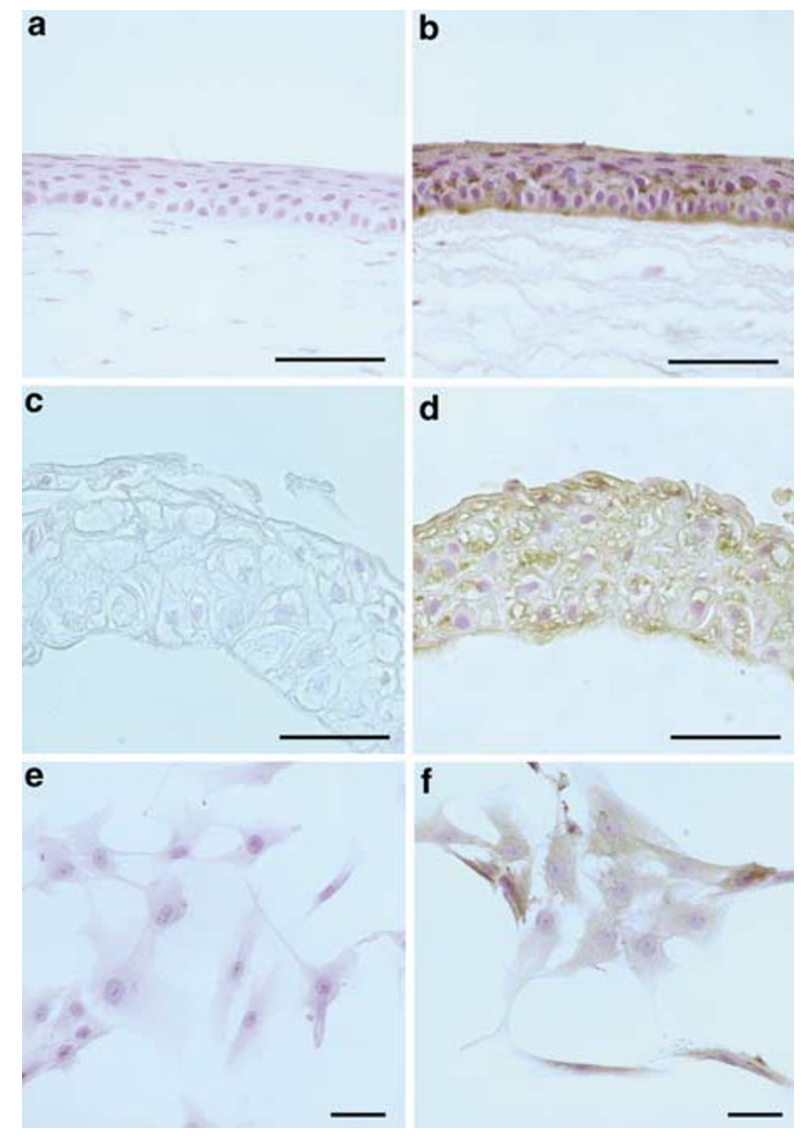

Figure 1 Immunolocalisation of LIF. ((a), (b)) Photo micrograph showing LIF expression in mouse corneal epithelium (b), the superficial layers stain stronger than basal layers. Endothelium and stoma are negative for LIF immunostaining, (a)-control. ((c), (d)) Photomicrograph showing expression of LIF cultured corneal epithelial sheets, (c)-control. ((e), (f)) Cultured corneal fibroblast expressing LIF (e), (f) control (Scale bar $50 \mu \mathrm{m}$ ). 


\section{Discussion}

In this study, we were able to immunolocalise LIF in cultured human corneal epithelial cells and fibroblasts. The expression of LIF in epithelial cells and fibroblasts, which were not subjected to injury or other stimulatory cytokines, was intriguing. LIF was also expressed in organ-cultured corneal epithelium (results not shown). We then examined whether LIF is expressed in normal corneal epithelium. As we were not able to obtain fresh human corneal tissue, the mouse cornea was examined. This showed that LIF is expressed in vivo in the corneal epithelium. Recent studies have shown the regulatory importance of LIF in stem cell proliferation, vascular genesis, inflammation, and immunity. ${ }^{8-11}$ However, the role played by LIF in the cornea is largely unexplored.

The sources of the adult corneal epithelial cells are the stem cell population residing at the limbus. The factors that regulate the corneal limbal stem cell have not been well elucidated. At lease two in vitro LIF culture systems were shown to enhance stem cell proliferation. In a coculture system containing murine fibroblast and embryonic stem cells, addition of LIF promotes the proliferation of ES cells by several fold. ${ }^{15}$ This property is unique to LIF and only occurred in the presence of fibroblasts. Further addition of LIF, to human haematopoietic stem cells CD34 $(+)$ thy-1 $(+)$ and murine bone marrow-derived stromal cell coculture caused expansion of haematopoietic stem cells in vitro. ${ }^{16}$ This stem cells expansion was specific to LIF and was observed only in the presence of fibroblast or stromal cells that are mesenchymal in origin. The action of LIF is indirect and mediated by mesenchymal cells. We observed that coculturing human limbal epithelial cells and limbal fibroblasts gave more prolific colonies in the presence of LIF (unpublished data). The interplay between corneal limbal stem cell and limbal fibroblast appears analogous to the interaction between haematopoietic stem cell and stromal cells, which is modulated under LIF. A stem cell expansion-promoting factor may be the possible link between the fibroblasts and corneal stem cell under the modulation of LIF.

The cornea is uniquely organised to discourage the induction and expression of inflammatory responses, particularly immune effector mechanisms that inflict significant injury to adjacent cells. The creation of such an immunological blind spot should render the cornea vulnerable to opportunistic infections and neoplasms. However, the conspicuous absence of neoplasm and the relatively low incidence of opportunistic infections suggest the existence of an effective immunological surveillance at the corneal surface. This property may be attributed to the presence of LIF in the corneal epithelial cells. Recently, the viral inhibitory potential of LIF has been demonstrated. ${ }^{17,18}$ In vitro LIF exerted a potent, GP130 dependent, inhibition of HIV-I replication. ${ }^{17}$ LIF also inhibits HIV-I in placenta and thymus tissue grown in ex vivo organ culture. ${ }^{17}$ Further, LIF is upregulated in human marrow stromal cells infected with human cytomegalovirus. ${ }^{18}$ In subacute sclerosing panencephalitis, LIF mRNA expression is upregulated in neurones infected with measles virus. ${ }^{19}$ LIF may act as a pro- or anti-inflammatory factor depending on the profile of tissue and other cytokines. This inflammatory role has been documented in CNS tissues and in skin. ${ }^{11,19-24}$

New vessel formation in the cornea is a significant factor contributing to visual morbidity. Although factors such as VEGF, which modulates cornea, and new vascularisation has been characterised, the process of vascularisation is far from clear. Several studies have indicated that LIF could play a role in the regulation of blood vessel formation, ${ }^{25-29}$ and LIF may have an implication in pathological vascularisation in ocular tissues. Depending upon the tissue origin or stage of differentiation, LIF has been shown to exert different actions. LIF stimulates adrenal cortex endothelial cells and embryonic cells, while it inhibit aortic endothelial cells. ${ }^{25-27}$ Embryonic endothelial cell line can be optimally induced to differentiate into capillary-like structures in vitro by combined exposure to LIF plus bFGF $^{26,28}$ During the formation of capillary structures from embryonic endothelial cell, line two-Stat3 and ${ }^{P} 41 / 43$ MAPK cascade systems are activated. ${ }^{29}$ Stat 3 acts as negative regulators on capillary development, and inhibition of this pathway is accompanied by increases capillary outgrowth, while inhibition of ${ }^{P} 41 / 43$ MAPK pathway dramatically reduces the capillary formation. ${ }^{29}$ Fine tuning of the extent of capillary growth depends on the regulation of these pathways and the cytokine profile. LIF can activate both cascades, thereby acting as a negative as well as a positive regulator of vascular genesis. ${ }^{28,29}$ Further studies examining the role of LIF in the corneal vascularisation may have therapeutic implications.

LIF is constitutively expressed in the corneal epithelium. It may play a role in modulating corneal stem cell dynamics, inflammation, and vascularisation. Further studies are necessary to determine the role of LIF in cornea during health and pathological processes.

\section{Acknowledgements}

This work was supported by Ophthalmology research grant-Royal College of Surgeons Edinburgh. Sponsored by Royal Blind Asylum \& Scottish National Institution for war Blind. (K Ramaesh, J West. B Dhillon: Leukaemia inhibitory factor and corneal epithelial stem cell proliferation) 


\section{References}

$1 \mathrm{Hu}$ J, Ono S, Katayama H, Imai T, Shimizu N, Nakagawa H. Leukemia inhibitory factor induces epidermal hyperplasia in patients with amyotrophic lateral sclerosis. J Invest Dermatol 2000; 115(3): 486-492.

2 Gillett NA, Lowe D, Lu L, Chan C, Ferrara N. Leukemia inhibitory factor expression in human carotid plaques: possible mechanism for inhibition of large vessel endothelial regrowth. Growth Factors 1993; 9(4): 301-305.

3 Knight DA, Lydell CP, Zhou D, Weir TD, Robert Schellenberg R, Bai TR. Leukemia inhibitory factor (LIF) and LIF receptor in human lung. Distribution and regulation of LIF release. Am J Respir Cell Mol Biol 1999; 20(4): 834-841.

4 Paglia D, Kondo S, Ng KM, Sauder DN, McKenzie RC. Leukaemia inhibitory factor is expressed by normal human keratinocytes in vitro and in vivo. Br J Dermatol 1996; 134(5): 817-823.

5 Gadient RA, Patterson PH. Leukemia inhibitory factor, Interleukin 6, and other cytokines using the GP130 transducing receptor: roles in inflammation and injury. Stem Cells 1999; 17(3): 127-137.

6 Li DQ, Tseng SC. Differential regulation of cytokine and receptor transcript expression in human corneal and limbal fibroblasts by epidermal growth factor, transforming growth factor-alpha, platelet-derived growth factor B, and interleukin-1 beta. Invest Ophthalmol Vis Sci 1996; 37(10): 2068-2080.

7 Li DQ, Tseng SC. Three patterns of cytokine expression potentially involved in epithelial-fibroblast interactions of human ocular surface. J Cell Physiol 1995; 163(1): 61-79.

8 Shih CC, DiGiusto D, Forman SJ. Ex vivo expansion of transplantable human hematopoietic stem cells: where do we stand in the year 2000. J Hematother Stem Cell Res 2000; 9(5): 621-628.

9 Shih CC, Hu MC, Hu J, Weng Y, Yazaki PJ, Medeiros J et al. A secreted and LIF-mediated stromal cell-derived activity that promotes ex vivo expansion of human hematopoietic stem cells. Blood 2000; 95(6): 1957-1966.

10 Smith AG, Nichols J, Robertson M, Rathjen PD. Differentiation inhibiting activity (DIA/LIF) and mouse development. Dev Biol 1992; 151(2): 339-351.

11 McKenzie RC, Paglia D, Kondo S, Sauder DN. A novel endogenous mediator of cutaneous inflammation: leukemia inhibitory factor. Acta Derm Venereol 1996; 76(2): 111-114.

12 Pellegrini G, Bondanza S, Guerra L, De Luca M. Cultivation of human keratinocyte stem cells: current and future clinical applications. Med Biol Eng Comput 1998; 36(6): 778-790.

13 Rheinwald JG. Serial cultivation of normal human epidermal keratinocytes. Methods Cell Biol 1980; 21A: 229-254.

14 Li DQ, Tseng SC. Differential regulation of keratinocyte growth factor and hepatocyte growth factor/scatter factor by different cytokines in human corneal and limbal fibroblasts. J Cell Physiol 1997; 172(3): 361-372.
15 Nichols J, Evans EP, Smith AG. Establishment of germ-linecompetent embryonic stem (ES) cells using differentiation inhibiting activity. Development 1990; 110(4): 1341-1348.

16 Shih $\mathrm{CC}, \mathrm{Hu} \mathrm{MC}, \mathrm{Hu}$ J, Medeiros J, Forman SJ. Long-term ex vivo maintenance and expansion of transplantable human hematopoietic stem cells [see comments]. Blood 1999; 94(5): 1623-1636.

17 Patterson BK, Behbahani H, Kabat WJ, Sullivan Y, O'Gorman MR, Landay A et al. Leukemia inhibitory factor inhibits HIV-1 replication and is upregulated in placentae from nontransmitting women. J Clin Invest 2001; 107(3): 287-294.

18 Lagneaux L, Delforge A, Snoeck R, Bosmans E, Moreau JF, Taupin JL et al. Human cytomegalovirus increases constitutive production of interleukin- 6 and leukemia inhibitory factor by bone marrow stromal cells. Blood 1996; 87(1): 59-66.

19 McQuaid S, Campbell R, Isserte S, Cosby SL. Leukaemia inhibitory factor mRNA is expressed in the brains of patients with subacute sclerosing panencephalitis. J Neuroimmunol 1997; 77(1): 57-62.

20 Banner LR, Patterson PH. Major changes in the expression of the mRNAs for cholinergic differentiation factor/ leukemia inhibitory factor and its receptor after injury to adult peripheral nerves and ganglia. Proc Natl Acad Sci USA 1994; 91(15): 7109-7113.

21 Banner LR, Moayeri NN, Patterson PH. Leukemia inhibitory factor is expressed in astrocytes following cortical brain injury. Exp Neurol 1997; 147(1): 1-9.

22 Curtis R, Scherer SS, Somogyi R, Adryan KM, Ip NY, Zhu Y et al. Retrograde axonal transport of LIF is increased by peripheral nerve injury: correlation with increased LIF expression in distal nerve. Neuron 1994; 12(1): 191-204.

23 Kurek JB, Austin L, Cheema SS, Bartlett PF, Murphy M. Upregulation of leukaemia inhibitory factor and interleukin-6 in transected sciatic nerve and muscle following denervation. Neuromuscul Disord 1996; 6(2): 105-114.

24 Kurek JB, Bennett TM, Bower JJ, Muldoon CM, Austin L. Leukaemia inhibitory factor (LIF) production in a mouse model of spinal trauma. Neurosci Lett 1998; 249(1): 1-4.

25 Pepper MS, Ferrara N, Orci L, Montesano R. Leukemia inhibitory factor (LIF) inhibits angiogenesis in vitro. J Cell Sci 1995; 108(Part 1): 73-83.

26 Gendron RL, Tsai FY, Paradis H, Arceci RJ. Induction of embryonic vasculogenesis by bFGF and LIF in vitro and in vivo. Dev Biol 1996; 177(1): 332-346.

27 Ferrara N, Winer J, Henzel WJ. Pituitary follicular cells secrete an inhibitor of aortic endothelial cell growth: identification as leukemia inhibitory factor. Proc Natl Acad Sci USA 1992; 89(2): 698-702.

28 Paradis H, Arceci RJ, Adams LC, Gendron RL. Differentiation responses of embryonic endothelium to leukemia inhibitory factor. Exp Cell Res 1998; 240(1): 7-15.

29 Paradis H, Gendron RL. LIF transduces contradictory signals on capillary outgrowth through induction of stat3 and (P41/43)MAP kinase. J Cell Sci 2000; 113(Part 23): 4331-4339. 